Volume 3

Issue 4 -- Cardiovascular Aging

Article 21

$11-11-2016$

\title{
WISE-Family Medicine: A Statewide Faculty Development \\ Collaborative
}

Deborah Simpson

Kjersti Knox

Anne Getzin

John R. Brill

Melissa M. Stiles

Jeffrey A. Morzinski

Follow this and additional works at: https://aah.org/jpcrr

Part of the Interprofessional Education Commons

\section{Recommended Citation}

Simpson D, Knox K, Getzin A, Brill JR, Stiles MM, Morzinski JA. WISE-Family Medicine: a statewide faculty development collaborative. J Patient Cent Res Rev. 2016;3:241.

Published quarterly by Midwest-based health system Advocate Aurora Health and indexed in PubMed Central, the Journal of Patient-Centered Research and Reviews (JPCRR) is an open access, peer-reviewed medical journal focused on disseminating scholarly works devoted to improving patient-centered care practices, health outcomes, and the patient experience. 
$\mathrm{CRC}$ death, making early $\mathrm{CRC}$ screening an imperative. While the Wisconsin Collaborative for Healthcare Quality ranks Aurora Health Care as eighth out of 20 systems in Wisconsin (77.6\% from 2014 Q3 to 2015 Q2), local data analysis identified age as the largest disparity gap. Analyzing local population REAL/gender data provides key insights to support initiatives to reduce health disparity gaps and further progress toward achieving the Triple Aim for health care.

\section{WISE-Family Medicine: A Statewide Faculty Development Collaborative}

Deborah Simpson, Kjersti Knox, Anne Getzin, John R. Brill, Melissa M. Stiles, Jeffrey A. Morzinski

Departments of Academic Affairs and Family Medicine, Aurora UW Medical Group; Department of Family Medicine and Community Health, University of Wisconsin School of Medicine and Public Health; Department of Family and Community Medicine, Medical College of Wisconsin

Background: In many states, family medicine residencies and medical schools compete clinically for patients, educationally for trainees and, more recently, for community preceptors (CPs). As Wisconsin's medical schools and health care systems have expanded their geographic footprints, our CPs now teach trainees from competing institutions. Yet residency and medical student accrediting bodies require faculty and preceptor development.

Purpose: To evaluate the impact of a statewide collaborative of family medicine educators on meeting faculty development needs of our CPs and collaborative members.

Methods: Faculty development leaders representing the three largest family medicine residency training sponsors in the state created the Wisconsin Institute of Scholars \& Educators in Family Medicine (WISE-FM). This statewide collaborative of family medicine educators is comprised of 3 to 4 representatives per sponsor — both junior and senior educators to further support their development as faculty - committed to developing common preceptor clinical teaching tools. Through online discussions and half-day WISE-FM meetings, WISEFM participants identified preceptor development needs and designed highly regarded clinical teacher infographics for these priority topics. These tools are available for use statewide, providing CPs with a consistent teaching approach. To determine infographic value, a brief ( $<5$ items) parallel form survey was distributed to and voluntarily completed by: 1) CPs who received the infographics, and 2) WISE-FM participants. Item results on a 5 -point Likert scale ( $5=$ strongly agree, $1=$ strongly disagree) were analyzed using descriptive statistics.

Results: Forty-two CP infographics recipients and the 11 WISEFM participants completed the evaluations. Results revealed that faculty development infographics were a time-efficient (CP: 4.1, WISE-FM: 4.2) and effective way (CP: 4.0, WISEFM: 4.2) to enrich skills as clinical teachers. Both groups intend to or have incorporated the infographics into their own teaching (CP: 4.2, WISE-FM: 4.2). WISE-FM respondents strongly agreed (4.6) that the overall "returns" from participating were worth their investments (time, effort).

Conclusion: The WISE-FM provides a statewide faculty development model that can be adopted by others to meet accreditation requirements for CP teaching skill development through shared authoring of $\mathrm{CP}$ development resources while concurrently advancing the development of WISE-FM participants.

\section{Evaluation of Preoperative Anemia and Transfusion Requirements in Adult Liver Transplant Recipients}

\section{Parissa M.N. Moghimi, Erika A. Aldag, Rachel Pedersen, Ajay Sahajpal, Jacob N. Clendenon, Vikraman Gunabushanam, Mehraboon S. Irani, David J. Kramer}

Departments of Pharmacy, Abdominal Transplant, Transfusion Services and Critical Care Medicine, Aurora Health Care

Background: Liver transplantation is often associated with massive blood loss due to surgical complexity and the hemostatic abnormalities of end-stage liver disease. Blood transfusions have been associated with increased risk of infection, multiorgan dysfunction, graft loss and mortality.

Purpose: To determine for liver transplantation whether correlation exists between preoperative anemia and transfusion requirements, length of stay or incidence of postoperative infection.

Methods: A retrospective review of liver transplantations from Jan. 1, 2012, to June 30, 2015, was conducted. Packed red blood cell (PRBC), fresh frozen plasma (FFP), platelet and cryoprecipitate units were collected preoperatively, intraoperatively and within the first 48 hours postoperatively. Cox proportional hazards model was used to model the outcome of infection. Linear regression was used to model the outcomes of postoperative length of stay and blood use.

Results: Of the 112 patients, mean age was 56 years, mean Model for End-Stage Liver Disease score was 27 and mean preoperative hemoglobin was $10.5 \mathrm{~g} / \mathrm{dL}$. Lower preoperative hemoglobin was significantly associated with increased preoperative $\mathrm{PRBC}$, platelet and cryoprecipitate use $(\mathrm{P}<0.04)$ as well as increased intraoperative PRBC, FFP, platelet and cryoprecipitate use $(\mathrm{P}<0.0001)$. Preoperative PRBC, FFP, and platelets as well as intraoperative PRBCs were associated with longer length of stay $(\mathrm{P}<0.045)$. Each $\mathrm{g} / \mathrm{dL}$ decrease in preoperative hemoglobin was associated with a $26 \%$ increased risk of infection in univariate models (hazard ratio $[\mathrm{HR}]$ : 1.26, $\mathrm{P}=0.01$ ). Longer length of stay and higher preoperative cryoprecipitate, intraoperative FFP and postoperative FFP also were associated with increased risk of infection. More units of preoperative cryoprecipitate (HR: $1.07, \mathrm{P}<0.01)$, fewer units of postoperative cryoprecipitate (HR: $0.19, \mathrm{P}<0.01$ ) and more units of postoperative FFP (HR: 1.75, $\mathrm{P}<0.01$ ) were associated with infection in multivariable stepwise selection.

Conclusion: Lower preoperative hemoglobin was associated with increased preoperative and intraoperative transfusion 